\title{
Collaborative Inquiry Driving Leadership Growth and School Improvement
}

\author{
M. Chaseling, R. Smith, W. Boyd, A. Foster, W. E. Boyd, C. Markopoulos, B. Shipway, \\ C. Lembke \\ Southern Cross University, Lismore, Australia \\ Email: wendy.boyd@scu.edu.au
}

Received 16 December 2015; accepted 12 February 2016; published 17 February 2016

Copyright (C) 2016 by authors and Scientific Research Publishing Inc.

This work is licensed under the Creative Commons Attribution International License (CC BY). http://creativecommons.org/licenses/by/4.0/

(c) (i) Open Access

\section{Abstract}

Australia's largest schooling system, the NSW Department of Education, is in a period of unprecedented change as the Department of Education initiates a range of reforms. One critical reform occurred in 2014 when the Department of Education and the New South Wales Teachers' Federation agreed to link teachers' salaries with accreditation. For the first time, all Department of Education principals, executives and teachers must complete an annual Performance and Development Plan. This article describes the work of a team of academics from the School of Education, Southern Cross University, and the Department of Education school leaders in northern NSW, exploring opportunities to accomplish school improvement through the "North Coast Initiative for School Improvement" (NCISI). The impetus for this initiative is based on the work of Alberta academics and researchers, Dr. David Townsend and Dr. Pamela Adams. The approach is based upon small teams, comprising a member of a school district's central office, a district principal and university academics, who once a month visit the leadership team of a school in order to build instructional leadership. This process involves the use of a guiding question, generative dialogue and a collaborative inquiry methodology. Early findings indicate the NCISI's approach is having positive impact leadership growth, through collaboration. Key elements of trust and professional identity have developed within teams. The very positive reaction of school communities to the project in its early stages is heartening and shows that there is a strong desire by school leaders to draw upon collaborative support in order to grow professionally. The project also demonstrates a strong level of commitment from a regional university to build productive relationships with schools.

\section{Keywords}

Instructional Leadership, School Improvement, Collaborative Inquiry, School/University Partnerships 


\section{Introduction}

Australia's largest schooling system, the NSW Department of Education, is in a period of unprecedented change as the Department of Education initiates a range of reforms (NSW Department of Education, 2015a). This is presenting major opportunities for teacher education. One critical reform occurred in 2014 when the Department of Education and the New South Wales Teachers' Federation agreed to link teachers' salaries with accreditation (New South Wales Industrial Relations Commission, 2014). Now, for the first time, all Department of Education principals, executives and teachers must complete an annual Performance and Development Plan (PDP). This three-stage goal-oriented process requires each principal, executive and teacher to work in a "collaborative and supportive environment” to 1) develop and articulate professional goals; 2) develop and articulate professional development strategies to achieve these goals; and 3) collect evidence to show progress towards achieving the goals (NSW Department of Education, 2015b).

Prior to this system-wide requirement, a team of academics from the School of Education, Southern Cross University, and the Department of Education school leaders in northern NSW, had explored opportunities to accomplish school improvement, and these efforts resulted in the launch in March 2015 of the "North Coast Initiative for School Improvement” (NCISI). Serendipitously, the NCISI's aim of supporting school improvement through a process of collaborative inquiry to promote leadership growth in schools aligns precisely with the Department of Education's now mandated annual goal-and-evidence focused Performance and Development Plan.

However, the impetus for the NCISI was not any foreknowledge of the Department of Education's Performance and Development Plan. Rather the NCISI is based largely on the work of Alberta academics and researchers, Dr. David Townsend and Dr. Pamela Adams. Their approach is based upon small teams, comprising a member of a school district's central office, a district principal and university academics, who once a month visit the leadership team of a school in order to build instructional leadership. This process involves the use of a guiding question, generative dialogue and a collaborative inquiry methodology (Townsend \& Adams, 2008). In Australia, the NCISI project aligned with this Alberta approach, and initially received seed funding of $\$ 10,000$ (January 2015) in order to establish the project. Subsequently the NCISI has become one of only three projects awarded \$100,000 under the NSW Department of Education’s System Leadership and University Partnerships Grants.

\section{The Aim of This Research}

The overall aim of the North Coast Initiative for School Improvement (NCISI) is to explore how a sustained focus on professional growth results in school improvement. For the academics from Southern Cross University involved in this initiative their guiding question is:

In what ways and to what extent can university researchers (i.e. academics) support the professional growth of teachers in schools?

\section{The Objectives}

The objectives of this study which are reported in this paper were:

1) to describe the initial stages of engagement and the involvement of academics and school leaders in the NCISI. Specifically, it explores the collaborative inquiry process that leads to leadership growth and school improvement;

2) to analyze the initial survey data gathered from the collaborative inquiry process

a) including indicators of leadership commitment, and

b) potential trends in professional growth and areas of priority for school improvement; and finally,

3) to determine, from the perspective of the academics involved, the key markers of change, resulting from the collaborative inquiry meetings with school leaders.

More than 80 volunteer educators from 30 schools are participating in the NCISI. They are visited monthly, for one to two hours, by a small external team made up of academics, local Department of Education officials and school leaders. During the initial site visit, school teams were supported to develop guiding questions linked to their Professional Development Framework goals. In subsequent site visits, school teams have been encouraged to reflect on the following four questions:

1) What have you done since last time we met? 
2) What have you learnt?

3) What is your evidence of learning or impact?

4) What will you do in the next 30 days?

After each meeting, school teams are provided with a copy of any transcripts, audio recordings or video recordings of the meeting.

\section{The Literature and Theoretical Framework.}

\subsection{Partnerships Come in Many Forms}

Literature regarding university academics working collaboratively with educators in schools indicates that these relationships exist in many forms, ranging from professional development to joint research (Bevins \& Price, 2014; Fancourt, Edwards, \& Menter, 2015). An early example of school/university partnerships took place in Australia in 1994-1996 when a consortium of 14 universities worked with more than 100 government and non-government schools. Funded by the Australian National Professional Development Program, and known as Innovative Links between Universities and Schools for Teacher Professional Development, this was a largescale action research project and was structured around the concept of Roundtables, with academic associates supporting teachers in their school-based projects (Grundy, Robinson, \& Tomazos, 2001). Also in Australia, teachers and academics have engaged as professional partners in order to develop curriculum to improve science, technology, engineering and mathematics (STEM) teaching in schools (Bissaker, 2014). In England, a standard university-school partnership teacher education partnership grew to also address some needs for professional development, and for university research (Fancourt, Edwards, \& Menter, 2015). In Ohio, USA, universityschool collaboration involved a ten-week appreciative inquiry study of 11 self-selected (voluntary) "school administrators" (in Australia these people are known as "principals") and this study used successful practices/ events to advance these school administrators' practices (Calabrese, 2015).

Research indicates that the learning, which occurs in close 'proximity' to the classroom, is the most effective in bringing about change in practice (Stoll, Bolam, McMahon, Wallace, \& Thomas, 2006). Additionally, building teacher capacity, with a focus on classroom practice, benefits both student outcome sand teachers' professional growth and satisfaction (Hattie, 2009; Dinham, 2008; Townsend \& Adams, 2009). It can be deduced that school leaders, who engage with purposeful, reflective and collaborative professional growth programs, there by position themselves, and their school communities, to have a positive and measurable impact on student learning outcomes. Importantly, such an approach enables school leaders and teachers to establish a strategic focus to put at the heart of their professional practice. Fullan (2001) describes such leaders as possessing a set of personal characteristics which he labels as the "energetic-enthusiastic-hopeful constellation", and comments that this can be "infectiously effective" (p. 7) in their leadership role.

\subsection{Academics/Teacher Collaboration}

Collaboration between teacher/principals and academics has increased over the last few years (Bevins \& Price, 2014). One advantage of this collaboration has been identified as minimizing the gap between theory and practice, and providing worthwhile opportunities for ongoing theory-making through research (Bevins \& Price, 2014).

Paradoxes exist in the relationship between schools and universities. Universities with teacher-education programs rely on schools, and their principals to accept pre-service teacher education students to complete their professional experience in schools. It is an imperative that there is a positive and workable relationship between the school and the university. Yet, while the principal provides approval for accepting a pre-service student, there is often not a close relationship between the actual principal and the university, owing to other layers of management taking control. The paradox exists that university is the institution that provides teachers with their education, yet universities may be viewed critically by the teaching profession.

Based on his ethnographic research, Wolcott (1973 in Wolcott, 2003) noted a paradox of the principal-university relationship. The principal's key focus is to promote the educational attainment of their students, and principals themselves hold formal academic qualifications. However, principals often hold their most recent experience of university in low esteem as, for some, their [American] graduate experiences were disappointing and irrelevant—a "necessary evil" for pragmatic objectives. Despite this, faculty members from universities might be invited as guest speakers to schools, or to sit on an interview panel to assess potential new staff. In these situ- 
ations formal academic achievements are viewed as indicative of expertise and are used as criteria for selection. Further, those with a formal academic qualification surpassing their own, such as a doctorate, may be treated with deference (Wolcott, 2003).

There are now examples of university-school relationships that are bearing strong results for school improvement. As outlined in the introduction, one of the strongest examples of university-school relationships is the work undertaken over many years in various Alberta school districts by Townsend and Adams. An 18 month university-school collaborative inquiry initiative undertaken in seven rural schools identified school improvement which includes: 1) five schools increased their collaborative behaviour and, as a consequence, increased their ability to meet their goals and 2) four schools demonstrated higher student achievement on external examinations. For the two schools that exhibited minimal improvements, this lack of improvement was related to team member and leadership changes and team conflict that could not be resolved or an inability to maintain focus on their goal (Townsend \& Adams, 2008).

Subsequently Townsend and Adams have been involved in a number of extensive university-school collaborative inquiry projects in various Alberta school districts. The findings at the end of the second phase of a government-funded research project (2010-2015) across all the schools in the Chinook's Edge School Division included: 1) that superintendents and other central office personnel can impact on the quality of instructional practices in schools and, in various specific ways, on the level of student learning, when they collaborate directly and frequently with school leader teams; 2) the power of a guiding question as a strategy to develop communication skills in a generative dialogue to support the reflective practices of individuals and the organization; 3 ) the value of re-culturing a central school office model such that these educators spend more, high quality, and purposeful time working with school leaders and teachers to achieve school and system goals; and, 4) the high importance of a competency-based model that links standards with student learning (Adams, 2015).

In a separate Alberta Government funded research project, conducted over three years (2013-2015) in all schools in the Red Deer Public School District, school improvement results directly associated with the project included: 1) leadership practices were refined to what can now be described as transformational; 2) leadership teams became more functional; 3) school leaders' capabilities were built; and 4) through the adoption of the collaborative inquiry model, there was a clearer focus on the needs of every student. Townsend asserts that this Red Deer Public School District Project has demonstrated how public education can be transformed (Townsend, 2015). This theoretical approach has been used to frame the North Coast Initiative for School Improvement.

\section{Methods/Methodology}

As academics working collaboratively with school leaders, the authors of the paper chose focused ethnography as the methodology for this study (Wall, 2015). Based on the pioneering anthropological study Wolcott (2003) on the life of a school principal, this interpretive paradigm requires time in the field for the complexities of social structures and relations to be understood (Jeffrey \& Troman, 2004). With its concern with people, the ethnographicness of the life stories is derived from the individual's social setting (Wolcott, 2004).

For this NSW project, in order to collect the crucial elements that will lead to the analysis of the characteristics that contribute to school leader's professional growth, focused ethnography is considered a suitable research tool. Such ethnographies are problem-centred and context-based on a discrete community or organisation or social phenomena, and involve a limited number of participants who usually hold special knowledge (Cruz \& Higginbottom, 2013). In this situation the researchers are also participants, and in a constrained but rigorous way are co-creating the knowledge which emerges. As part of this process educators reflect on their practice and actions.

John Dewey described reflection as the "active, persistent and careful consideration of any belief or supposed form of knowledge in the light of the grounds that support it” (Dewey, 1933: p. 113). Schön (1983) progressed Dewey's ideas about "reflection-in-action" for professionals and Argyris and Schön (1987) further refined the ideas for application by education professionals. Writing in 2015, McLeod, Barr and Welch (2015) conducted an integrated literature review to better understand current initiatives for teaching reflective practice in health. They found a shift from a focus on written reflections to more dialogue and social-based reflections. This paper will not attempt to cover the history of reflective practice but it is important to note that these ideas permeate the methodology of both the Alberta Initiative and the NCISI.

In the initial phase of the NCISI, school leaders have determined their professional development goals (as 
now required by the Department of Education). From this step they have then drafted and refined their guiding question/s, and then determined both their strategies and what will count as appropriate evidence. Each monthly meeting is recorded, and returned to the principal to ensure accurate recording. This record may be audio or video, and provides rich data for the long-term analysis of the development of individual participants and for examination of the collaborative approach on which the initiative is based.

Many data collection methods are being used in the NCISI, some are considered here, and others are ongoing for future in-depth analysis. Academics have collected data in the form of interview and field notes and videos. Longer term, the analysis of this data will be undertaken to determine characteristics that contribute to school leaders' professional growth and ultimately to student outcomes. Participants have also responded to surveys at presentations and a NCISI Symposium.

In this paper we present findings and analysis from two data collection tools:

1) We report on survey data from principals and teachers undertaken to determine their early reactions to the project. The survey was completed by 45 (56\%) participants at the six-month point of the project. This survey asked participants short answer open-ended questions about their motivation, desired outcomes, achievements to date and evidence for these achievements. This information is important as the project broadens to involve more schools and leaders who, though not initially involved in the project, have expressed interest in participation.

2) We asked the academics in the visiting teams for the highlight of their experience in the project-data they were able to source from their professional learning journals, which then forms part of the data presented in this paper.

\section{Findings}

Participants' motivation for involvement, desired outcomes, achievements to date and evidence for these achievements was collected in the survey distributed through Qualtrics to the participants. When prompted about their reasons for involvement with the initiative, participants focused on the prospects of improvement in their leadership for overall school improvement and improved student outcomes. Many cited the success of the Alberta initiative (Adams \& Townsend, 2014) as being influential in their decision to become involved with the NCISI. Some commented on the value of the collaborative culture involved which appeared to be more realistic than other approaches that they had tried. Typically, participants noted that the well-researched model was already seen to bring about educational change and one principal noted that she was involved to "provide staff greater opportunities to work collaboratively”.

When asked for factors that have led to almost $100 \%$ continued involvement of the original participants, responses focused on the process that involved the month meetings, and associated generative dialogue with the guiding questions. Participants consistently noted the establishment of a goal and guiding question that needed frequent consideration and reflection, justification, and specific validation on a monthly basis, with peers and team leaders. For the participants this was reported to lead to deeper commitment to the goal with benefits for themselves, the school or school responsibility area. As one participant explained “After every mentoring session, I have gone away enthused and inspired to keep working hard at my goal”. Other participants commented on the inputs from the team that allowed for a "blend of practicality and academic approaches," in order to "find solutions for very complex local issues”.

Though still at an early stage most participants were able to cite personal and professional achievements, with evidence. These mostly centred on personal progress on goals, but several noted developments in staff improvement or actual classroom outcomes because “the process kept them focused". An interesting comment made by several participants was that assisting others to find their own solutions-through the collaborative process, rather than suggesting solutions-was empowering for both parties. The establishment of a team goal within a faculty led one participant to comment that it:

Transformed executives meetings to be purposeful and "functional" with the executive staff now looking for this structure in other meetings-building a low tolerance to poor organisation and meetings without purpose. It has also [built] my confidence in [leading] whole staff meetings.

The question about evidence revealed a surprising variety of strategies that participants were using as part of their personal and school-based improvement goal. There was note of coaching diaries, cloud-based group diaries, video diaries, strong links with the employer-required Professional Development Plans, and purposeful 
use of research-based approaches, such as establishing base line data for school goals for regular checking of progress of strategies. It was interesting to note the extensive use of minutes and other records to confirm progress and commitment. One team cited the use of generative dialogue as being a factor in a successful funding application; another indicated that the process was very useful in dealing with the difficult process of placing and supporting a staff member on an improvement programme. One principal noted the increased ability of executive staff to better share responsibility for school operation.

The academic participants also contributed to this survey. They reported that their engagement in the initiative was motivated by the chance to assist in the establishment of a truly collaborative approach to school leadership and improvement. Some had already observed this process in place in Alberta and were certain of its relevance for schools within the university's North Coast (NSW) footprint. Also frequently cited by the academics were the opportunities 1) to connect with schools in a meaningful way, 2) to assist school teams, and also, 3) to better inform the teaching and learning in courses for pre-service teachers.

\section{Highlights from the Perspective of the Visiting Academics}

The professional learning journals of the eight academics (academics) involved in the visiting teams form the second part of the data presented in this paper. Each academic volunteered these preliminary impressions of the highlights of what they had observed at the six-month point. Because of their small number, their individual responses may be presented in full. Most notable in their reports was the sense of trust, specifically, cited by three:

Marilyn: The highlights for me are the professional relationships and the trust that have developed between the school leaders and the academics. School leaders tell us that it is "fantastic" having our monthly meetings and that they look forward to them, as an opportunity for professional dialogue. For me it is the opportunity to hear what is happening in school, to support leaders in their goals and generally to be helpful

Cathy: I was surprised with how quickly trust has developed within the group once we were meeting on a regular basis. It was the sense of familiarity and collegiality I think born out of the idea that this is a non- judgmental environment that leads to very honest opinions being expressed, which I don't think would be expressed in any other environment. In fact, one principal in my group commented that out of all the meetings he has to attend, this is the one that he likes the most and this would be the one that he would not miss!

Alan: As a former school principal, and now academic, on my team visits to schools I have been impressed with the trust that the school leaders have in the collaborative inquiry process. It is not easy for them to articulate very personal aspects of goal-setting and why those goals are being set. It would be easy for participants, who have been through many imposed improvement strategies in their careers, to be cynical about the process and also evidence the traditional wariness that practitioners have of academics. Rather than see evidence of this, there has only been a trusting welcome and, moreover, invitations to participate in other aspects of school planning.

Partly overlapping with this trust was the gratitude that the school-based participants expressed-that their professional role, competence and decisions were taken seriously by the team as a group of fellow professionals. While noted by only one as the highlight, this observation was generally supported by other academics:

Wendy: What has been apparent at each of the monthly school meetings I have attended is that the leaders of the schools are very committed to delivering education that engages student learning. They each realize the enormity of their position, and have agreed to incrementally pursue their guiding questions so that ongoing continuous improvements are made within the school. Interestingly they appear very humble that they are listened to, that the visiting team "turns up" each month so they can use this opportunity to further guide their focus on ongoing improvement.

Specific changes in behavior, professional attitude, and in the school's internal operation were cited by four academics:

Robert: [At a four-teacher rural school], during the early meetings, the teaching principal's statements were initially in the form of "I asked them [the teachers] to tell me ...", and, "They gave me answers that ...". As the collaborative process proceeded, with team-based visits, the principal's language changed remarkably. Rather than I/they statements, there was the emergence of the following inclusive phrasing, and now specifically quoted:

"We have decided we would do a recount." 
"We would ask some clarifying questions then we would ask some more problem questions."

"We all left feeling we were getting there."

"We videoed the two groups-maths and science."

"We've been collecting more data than we said we would".

The change was not complete, with occasional I/they statements still occurring, e.g., when the principal reflected on an earlier staff meeting when she had handed staff a blank sheet of paper and asked them to write a reflection on their professional learning during the year. The newer usage did not seem forced or artificial, and did seem genuine, which made the change seem all the more remarkable.

Brad: One of the clearest examples of manifested leadership emerged with a young Head Teacher whose guiding question involved embedding collaborative staff practices into his faculty. This Head Teacher of physical education came to his first collaborative inquiry meeting dressed tidily, but in shorts and a t-shirt. After the third meeting (in the third month), and after his first tentative efforts at explaining and trialing the collaborative inquiry approach with the staff in his faculty, this same teacher arrived for his third collaborative meeting excited and attired in a trim-cut silver business suit, pink button-down business shirt and complementary blade tie-an immediately impressive ensemble. Of course, given that this research was conducted in an Australian regional setting, it was mandatory for much good-natured teasing to ensue. Beyond the outside appearance, after compiling the notes of this teacher's generative dialogue, the research team noticed a dramatic increase in the formalized structure of his language compared to his first generative discussion. The teacher had eliminated colloquialisms, slang and contractions from his speech patterns and was now articulating himself in a much more formal and precise manner. When one of his colleagues asked "What happened to you", the Head Teacher responded "I'm getting serious”. This was part of him volunteering to step-up from his faculty leadership to acting Deputy Principal.

Christos: One principal remarked that, as a result of participating in the monthly collaborative inquiry meetings, he changed the professional development process of the school's senior staff meeting. Previously the principal set the goals and delivered them to his staff. However, now he told us, he takes a more collaborative approach, his senior leadership team share their goals together-common goals.

He also pointed out that there was a staff member who was initially quite negative, and who resisted the change to the staff meeting, but now he is fully engaged. The principal reflected that now he can see that this staff member has taken responsibility and is involved because of the new collaborative inquiry approach, not because the principal gave him the responsibility, but because the staff member himself changed. The principal can also see the impact of the collaborative inquiry approach in the lower levels in the school.

Bill: There are two highlights for me: First, just watching the remarkable growth of “my principals" who, even within a few months of engaging in the projects have demonstrated very positive change in their relationships with their colleagues and peers. One has taken control of her relationships, turning round all those discussions with "difficult” parents, “difficult” teachers and "difficult” supervisors into very positive, civilized and, most importantly, constructive conversations. Sharing the issues and the solutions, often over a cup of tea, has done wonders for the principal's self confidence and efficacy as a principal. The other has spun magic in his staff meetings, reducing meeting time, improving meeting focus, enhancing meeting outcomes, and giving ownership of the processes to his colleague. Both principals have a spring in their step

One change was noted which revealed a bridge between professional support and academic approaches, and which showed the benefit of an academic as a member of the supportive team:

Bill: Most notable was the realization that teachers see evidence as "a scary thing”. Once we had realized that, we were able to assist in identifying valid evidence and so reducing the anxiety of teachers. The teachers were beginning to realize that the narratives themselves can constitute evidence, if framed correctly. It became clear that teachers don't move and live in the "heavy" evidence, they want the stories, and so the narrative for teachers is way more important for them-“not interested in the numbers-interested in the stories”.

Finally, one response was offered which presented an answer to regular questions about the value of the process to the academic academics involved:

Robert: In response to a principal's question, "I’ve never seen university people so involved with schools. Please, tell me, what do you people get out of this?” The academics responded:

Academics are always keen to know what is happening in schools. However, the practicalities of time mean that it is rarely possible. For example, if I arrived at a Principal's office, introduced myself, and asked if I could have an hour while the Principal explained to me what he/she saw as the key challenge in the school, and the 
most important initiative, being undertaken, and then that I would return in one month for an hour-long update, imagine the reaction I would get. Accepted once, perhaps? Through the NCISI project, I get to do this every month at five schools.

\section{The Analysis/Discussion}

While the near $100 \%$ continuation of participants, who have volunteered to be involved in the North Coast Initiative for School Improvement, might be sufficient evidence alone of the project's initial success, there are several more specific implications that can be drawn from the data. First is the often-repeated emphasis upon collaborative culture and the trust that emerges from the process. This element is rarely evident in the literature on university-school partnerships, yet in this project it is reported as pre-eminent, and then might reasonably be seen to be the trigger for the other changes that follow. The origins of such trust appear to be in the sense of gratitude that one's professional activity, and its commitment to improved student outcomes, is both acknowledged and supported by knowledgeable peers. More broadly, this suggests that enhancing professional identity or standing will improve student outcomes, and systems of accountability, and indeed government policies nationally are moving towards such ends. However, an over-reliance here serves predominantly to make one a client to government forces. More traditionally, professional identity has been enhanced by professional associations and by university study towards higher degrees. Yet the early findings of this project would suggest that all those broader supports, traditional as well as government, are perhaps necessary but they are not sufficient. Every school community wants its focus to be on improved outcomes for its own students, as does the school leadership team. Such teams know that school improvement involves many indeterminate factors, with complex variables and multiple choices for action (all to a degree which would befuddle most other professions). So, more specifically, this project's initial success would seem to come from its focus upon clarifying, and purposefully supporting professional decision-making to the distinctive context and needs of the leader's school. The process values the local.

Secondly, the specific elements that contribute towards this trust from the participants would seem to be the knowledge that it has a research base and success in another country, the evident commitment of the team with its monthly visits, and the realistic focus upon the needs of the particular school. Put simply, if an opportunity to explain the school context, its key impediments to student outcomes, the best plan for addressing this, and does so to a non-judgmental external team, then the school leader feels obliged to progress the plan before the next team visit.

Thirdly there is the flow-on of the process to other groups within the school. While only some participants cited this as an early outcome, the overall process was seen as empowering in the dealings of leaders with those whom they worked closely or whom they supervised.

A final implication is in the role of the university academics as separate participants in this process. Here they are breaking several pre-conceptions: they are not presenting themselves as experts, aware of all the current research and so offering professional development for a fee; they are not "asking for something", such as permission to conduct research to serve their own purposes. However, they are importantly, focused upon process, and lend it an academic authority — that one can explicitly value ideas, inquiry, evidence, and that failure is not only acceptable but it can yield valuable insights.

\section{Conclusions}

This early evaluation is clearly strong. The NCISI has a purposeful focus on visible leadership growth, and on collaboration within schools with the aim to have a positive impact on student learning outcomes. Key elements of trust and professional identity are seen to be inherently dependent upon serving local needs and with regular face-to-face support. The very positive reaction of school communities to the project in its early stages is heartening and shows that there is a strong desire by school leaders to draw upon collaborative support in order to grow professionally. To some degree this collaborative approach is then replicated within school communities. The project also demonstrates a strong level of commitment from a regional university to build productive relationships with schools in order to benefit students.

With so many positives, it is still important to consider the limitations of the process. In Red Deer, Alberta, the project was made compulsory by the employer administrators; here it has been voluntary. This means that participants self-select into the project, based on reports of its success and perhaps the "halo effect" of others 
nominating to be included. The project does not yet have clear steps for one to disengage from participation, and this must be considered.

Another limitation is the need for clear evidence on improvements in student outcomes. Such outcomes are the ultimate goal, but they must not be either forced (and so not sustainable) or delayed too long. The evidence from Alberta is that it takes three years for the process to fully work through to such outcomes. This time frame presents considerable challenges to ensure that the NCISI project is well resourced and staffed. However, it must be noted that the stable school staffing of this NSW region means that professional commitment to a school goes well beyond that suggested timeframe.

With a view to increasing local voluntary participation, one limiting feature is the number of academics available to participate. Regional universities typically have small staffing establishments as well as large geographic areas to cover. The problem becomes magnified if the project considers up-scaling to serve other regions. Clearly partnerships between universities would be required in order to grow the same model. Ownership or governance would also be either limiting or enabling in such growth. It may be that a professional organization or a trust is the best structure to take over such an expanded project. In these considerations we move well beyond our Alberta model into what is the most appropriate and sustainable for our Australian context.

Still, with such overwhelming early positive findings, this is an exciting time for teacher professional development, as well as determining areas of priority for school improvement. It is a strong step for professional identity to see a home-grown initiative pre-empting and now support a critical reform by the NSW Department of Education.

\section{References}

Adams, P., \& Townsend, D. (2014). From Action Research to Collaborative Inquiry. Education Canada, 54. http://www.cea-ace.ca/education-canada/article/action-research-collaborative-inquiry

Adams, P. (2015). Developing School Leadership Competencies Using a Collaborative Inquiry Model: Exploring an Instructional Leadership Approach to Enhancing Teaching and Learning. Chinook’s Edge, AB: Chinook’s Edge School Division.

Argyris, C., \& Schon, D. (1987). Theory in Practice: Increasing Professional Effectiveness. San Francisco, CA: Jossey-Bass.

Bevins, S., \& Price, G. (2014). Collaboration between Academics and Teachers: A Complex Relation. Educational Action Research, 22, 270-284. http://dx.doi.org/10.1080/09650792.2013.869181

Bissaker, K. (2014). Transforming STEM Education in an Innovative Australian School: The Role of Teachers' and Academic Professional Partnerships. Theory in Practice, 53, 55-63. http://dx.doi.org/10.1080/00405841.2014.862124

Calabrese, R. (2015). A Collaboration of School Administrators and a University Faculty to Advance School Administrators Practices Using Appreciative Inquiry. International Journal of Educational Management, 29, 213-221. http://dx.doi.org/10.1108/ijem-03-2014-0028

Cruz, E. V., \& Higginbottom, G. (2013). The Use of Focused Ethnography in Nursing Research. Nursing Researcher, 20, 36-43. http://dx.doi.org/10.7748/nr2013.03.20.4.36.e305

Dewey, J. (1933). How We Think: A Restatement of the Relation of Reflective Thinking to the Educative Process. Boston, MA: D.C. Heath \& Co Publishers.

Dinham, S. (2008). How to Get Your School Moving and Improving: An Evidence-Based Approach. Camberwell, VIC: ACER Press.

Fancourt, N., Edwards, A., \& Menter, I. (2015). Reimagining a School-University Partnership: The Development of the Oxford Education Deanery Narrative. Education Inquiry, 6, 353-373. http://dx.doi.org/10.3402/edui.v6.27724

Fullan, M. (2001). Leading in a Culture of Change. San Francisco, CA: Jossey-Bass.

Grundy, S., Robinson, J., \& Tomazos, D. (2001). Interrupting the Way Things Are: Exploring New Directions in School/ University Partnerships. Asia-Pacific Journal of Teach Education, 29, 203-217. http://dx.doi.org/10.1080/13598660120091829

Hattie, J. (2009). Visible Learning: A Synthesis of over 800 Meta-Analyses Relating to Achievement. New York: Routledge.

Jeffrey, B., \& Troman, G. (2004). Time for Ethnography. British Educational Research Journal, 30, 535-548. http://dx.doi.org/10.1080/0141192042000237220

McLeod, G., Barr, J., \& Welch, A. (2015). Best Practice for Teaching and Learning Strategies to Facilitate Student Reflection in Pre-Registration Health Professional Education: An Integrative Review. Creative Education, 6, 440-454.

http://dx.doi.org/10.4236/ce.2015.64044 
NSW Department of Education (2015a). Performance and Development Framework for Principals, Executives and Teachers in NSW Public Schools. https://www.nswtf.org.au/files/performance-development-framework-and-template-update.pdf

NSW Department of Education (2015b). Our Reforms. http://www.dec.nsw.gov.au/about-the-department/our-reforms

New South Wales Industrial Relations Commission (2014). Crown Employees (Teachers in Schools and Related Employees) Salaries and Conditions Award 2014.

http://www.lawlink.nsw.gov.au/irc/ircgazette.nsf/LUPublications/968F4B979CE23BDACA257D090016115B?OpenDocu ment

Schön, D. (1983). The Reflective Practitioner: How Professionals Think in Action. New York: Basic Books.

Stoll, L., Bolam, R., McMahon, A., Wallace, M., \& Wallace, S. (2006). Professional Learning Communities: A Review of the Literature. Journal of Educational Change, 7, 221-258. http://dx.doi.org/10.1007/s10833-006-0001-8

Townsend, D. (2015). Red Deer Public Schools: Administrative Growth Research and Development Project: Final Report: Year III. Red Deer: Red Deer Public School District.

Townsend, D., \& Adams, P. (2008). Being There: University Faculty, School Administrators, and Teachers Engaged in School Improvement. Northwest Passage, 6, 53-64.

Townsend, D., \& Adams, P. (2009). The Essential Equation: A Handbook for School Improvement. Calgary: Detselig.

Wall, S. (2015). Focused Ethnography: A Methodological Adaptation for Social Research in Emerging Contexts. Forum: Qualitative Social Research, 16, Art. 1. http://nbn-resolving.de/urn:nbn:de:0114-fqs150111

Wolcott, H. (2003). The Man in the Principal's Office: An Ethnography (updated ed.). Walnut Creek, CA: Alta Mira Press.

Wolcott, H. (2004). The Ethnographic Autobiography. Auto/Biography, 12, 93-106.

http://dx.doi.org/10.1191/0967550704ab004oa 